HELMINTHOLOGIA, 53, 4: 318 - 325, 2016

\title{
Cardiorespiratory and gastrointestinal parasites of dogs in north-west Italy
}

\author{
L. GUARDONE', M. MAGI', M. C. PRATI², F. MACCHIONI"*
}

'Department of Veterinary Sciences, University of Pisa, Viale delle Piagge 2, 56124 Pisa, Italy, E-mail: lisa.guardone@for.unipi.it, marta.magi@unipi.it, *fabio.macchioni@unipi.it; ${ }^{2}$ Scuola Normale Superiore di Pisa, Piazza dei Cavalieri 7, 56126 Pisa, Italy, E-mail: mc.prati@sns.it

\section{Article info}

Received May 24, 2016 Accepted July 13, 2016

\begin{abstract}
Summary
The present study was conducted to evaluate the prevalence of gastrointestinal and cardio-respiratory parasites in dogs in Liguria (northwest Italy) which is a region that has scarcely been studied. A total of 450 dogs (260 males and 190 females) were enrolled in the study from 2009 and 2013. All dogs lived in a rural or semi-rural environment in the provinces of Imperia $(n=352)$ or Savona $(n=$ 98), Liguria. Coprological examinations showed that 197 dogs (43.8 \%, Cl 38.7-48.9 \%) were infected by parasites. Specifically, $3.3 \%$ of the dogs presented only cardio-respiratory species, $32.4 \%$ only intestinal species, and $8.0 \%$ presented a mixed infection.

The most frequent intestinal parasites were Toxocara canis (20\%), Trichuris vulpis (17.8\%), Ancylostomatidae (12\%), Coccidia (2.7 \%), Aonchotheca putorii (1.8\%) and Toxascaris leonina (1.8\%). The cardio-respiratory species found were Eucoleus aerophilus (9.6\%), Eucoleus boehmi (1.6\%), Angiostrongylus vasorum (0.7\%), and Crenosoma vulpis (0.2\%). A total of 116 dogs (25.8\%) were parasitized by a single species, multiple infections were observed in 81 dogs (18.0\%) up to a six-order infection.

This preliminary study highlighted that the prevalence of intestinal parasites in investigated area is high. Cardio respiratory parasites were detected in an area that has not been investigated before. The creation of a more extensive sampling programme of the area, on a provincial basis in order to build a more detailed map of prevalences for different species of dog parasites throughout Liguria, a more extensive sampling programme of the area needs to be created - ideally for each province.

Keywords: dogs; helminths; epidemiology; Liguria; Italy
\end{abstract}

\section{Introduction}

Dogs can host several helminth species, many of which are of zoonotic importance and may be a threat to human health causing serious diseases (Soriano et al., 2010; Mateus et al., 2014). In fact, dog parasites represent a potential risk to public health, especially in children or immuno-compromised people, since direct or indirect transmission of parasitic infections from dogs to humans can occur
(Martínez-Moreno et al., 2007; Xhaxhiu et al., 2011). Thus, there is continuing interest in implementing control measures (Traversa, 2012). The number of pets is increasing and dog faeces are an important pollution factor if not properly removed. Parasite eggs can stick to shoes, they can be carried by arthropods, or by wind and rain into homes. The fact that some owners do not remove dog faeces from streets and green areas represents a risk for public health (Deplazes et al., 2011). 
The most frequent intestinal nematodes of domestic canids are Ascarididae (Toxocara canis and Toxascaris leonina), Ancylostomatidae (Ancylostoma caninum and Uncinaria stenocephala), and Trichuridae (Trichuris vulpis) (Claerebout et al., 2009; Traversa, 2012). The larvae of $T$. canis and, less frequently, of $T$. leonina cause visceral and ocular larva migrans in humans, which can be particularly serious for children (Bowmann, 1987; Lee et al., 2010). Dog hookworms (Ancylostomatidae) cause cutaneous larva migrans (CLM) in humans, by actively penetrating the skin (especially Ancylostoma spp.) and/or via the oral route (Ancylostoma spp., Uncinaria spp.)(Bowmann et al., 2010). A. caninum can occasionally reach the adult stage and cause eosinophilic enteritis in humans (Bowmann et al., 2010). The zoonotic potential of $T$. vulpis is still debated (Traversa, 2011).

Other canine intestinal parasites of zoonotic importance are Taenidae (in particular Echinococcus granulosus and Echinococcus multilocularis) and Dipylidiidae (Dipylidium caninum) (Vervaeke et al., 2005; Eckert \& Deplazes, 2004).

Several cardio-respiratory nematodes also affect dogs. These include trichuroid nematodes Eucoleus aerophilus (syn. Capillaria aerophila) and Eucoleus boehmi (syn. Capillaria boehmi), which are mainly the parasitic nematodes of wild canids, e.g. foxes and wolves, but infections in domestic dogs have also been described (Magi et al., 2012; Macchioni et al., 2013; Veronesi et al., 2013). E. aerophilus may be responsible for rare zoonotic infections in humans (Aftandelians et al., 1977; Lalošević et al., 2008). Similarly, metastrongyloid nematodes Crenosoma vulpis and AngiostrongyIus vasorum infect both wild canids and dogs (Conboy, 2009; Magi et al., 2015).

Many surveys have been carried out on dog parasites around the world, and all highlight the importance of studying these parasites both from a veterinary and a public health perspective. This study describes the epidemiology of gastrointestinal and cardio-respiratory helminth infections in dogs living in a rural environment, with possible contact with foxes, in a region that has been scarcely investigated (Liguria, north-west Italy). In fact, foxes can act as a wild parasitic reservoir for pets, with significant implications for public and veterinary health (Deplazes et al., 2004; Vervaeke et al., 2005; Jenkins et al., 2011).

\section{Materials and Methods}

A total of 450 dogs (260 males and 190 females) were enrolled in the study from 2009 and 2013. All dogs lived in a rural or semi-rural environment in Imperia ( $n=352$ ) or Savona $(n=98)$, Liguria, north-west Italy. Only dogs which had not received any anthelmintic treatment for at least four months prior to the sampling were included in the study. For each dog at least one faecal sample and a blood sample were collected. The results regarding the analysis of the blood samples have already been published (Magi et al., 2016). Gender, age, breed, lifestyle and geographical origin were recorded. As for lifestyle, 344 dogs were hunting dogs, 92 dogs were sampled from various kennels of the study area, and 14 were pets (a total of 106 non hunting dogs). Animals were classified into three age classes: 1 year or less $(n=57)$, between 1 and 7 years $(n=269)$, and 7 years or more $(n=124)$.

The dogs' faecal samples were analyzed by flotation in centrifuge, using $50 \%$ zinc sulfate solution (s.g. 1.350) according to the procedure described by Dryden et al. (2005) Baermann's technique was also used for the detection of lung nematode larvae according to the procedure described by Taylor et al. (2007). Helminths were identified according to the usual keys (Yamaguti, 1959; Campbell, 1991).

As for the statistical analysis, parasitic prevalences with $95 \%$ confidence intervals $(\mathrm{Cl})$ were calculated. Multiple parasitic infections were described. Pearson's chi squared test or Fisher's exact test were carried out to compare parasitic prevalences among genders, age classes and groups of hunting and non-hunting dogs. The significance of the tests was confirmed for $P$ values $<0.05$. Calculations were performed with Microsoft Excel $\circledast$ and R 2.9.1 (R Development Core Team, 2009).

The sample size (450 dogs) was calculated in order to have a $99 \%$ probability of finding at least one infected dog in the examined sample, assuming the prevalence of a certain parasite in this region to be around $1 \%$ (a reasonable value for Angiostrongylus vasorum, e.g).

\section{Results}

A total of 197 out of 450 dogs $(43.8 \%, \mathrm{Cl} 38.7-48.9 \%)$ were found to be infected by some kind of parasite. Specifically, $3.3 \%$ of the dogs presented only cardio-respiratory species, $32.4 \%$ only intestinal species, and $8.0 \%$ presented a mixed with both

Table 1. Results of copromicroscopic examination by flotation in centrifuge of the faecal samples of 450 dogs (\%: prevalence value; $\mathrm{Cl}$ : Confidence Interval)

\begin{tabular}{lccc}
\hline Flotation results of 450 dogs & $\mathbf{N}$ tot. pos. & $\%$ & $\mathbf{C l}$ \\
\hline Cardio - respiratory parasites & & & \\
Eucoleus aerophilus & 43 & 9.6 & $6.8-12.3$ \\
Eucoleus boehmi & 7 & 1.6 & $0.4-2.7$ \\
Angiostrongylus vasorum & 3 & 0.7 & $0-1.4$ \\
Crenosoma vulpis & 1 & 0.2 & $0-0.7$ \\
Intestinal parasites & & & \\
Toxocara canis & 90 & 20.0 & $16.3-23.7$ \\
Trichuris vulpis & 80 & 17.8 & $14.2-21.3$ \\
Ancylostomatidae & 54 & 12.0 & $9.0-15.0$ \\
Coccidia & 12 & 2.7 & $1.2-4.2$ \\
Toxascaris leonina & 8 & 1.8 & $0.6-3.0$ \\
Aonchotheca putorii & 8 & 1.8 & $0.6-3.0$ \\
Hymenolepis diminuta & 5 & 1.1 & $0.1-2.1$ \\
Dipylidium caninum & 1 & 0.2 & $0-0.7$ \\
Physaloptera spp. & 1 & 0.2 & $0-0.7$ \\
\hline
\end{tabular}


Table 2. Statistical results of the comparisons among gender, lifestyle and age groups of 450 dogs with P values of Pearson's or Fisher's tests (ns: not significant, means that the test was not performed due to very low number of positive cases)

\begin{tabular}{|c|c|c|c|c|c|c|c|c|c|c|}
\hline \multirow{2}{*}{ Tests results on 450 dogs } & \multicolumn{3}{|c|}{ Gender } & \multicolumn{3}{|c|}{ Lifestyle } & \multicolumn{4}{|c|}{ Age } \\
\hline & $\begin{array}{c}\mathbf{F} \\
(n=190)\end{array}$ & $\begin{array}{c}M \\
n=260)\end{array}$ & $P$ values & $\begin{array}{l}\text { hunting } \\
(n=344)\end{array}$ & $\begin{array}{c}\text { non hunting } \\
(n=106)\end{array}$ & $P$ values & $\begin{array}{c}\leq 1 \text { year } \\
(n=57)\end{array}$ & $\begin{array}{c}1-7 \\
\text { years } \\
(n=269)\end{array}$ & $\begin{array}{c}\geq 7 \text { years } \\
(n=124)\end{array}$ & $P$ values \\
\hline \multicolumn{11}{|c|}{ Cardio-respiratory parasites } \\
\hline Eucoleus aerophilus & 25 & 18 & 0.0263 & 43 & 0 & 0.0001 & 12 & 23 & 8 & 0.005 \\
\hline Eucoleus boehmi & 1 & 6 & ns & 2 & 5 & 0.0093 & 2 & 2 & 3 & ns \\
\hline Angiostrongylus vasorum & 1 & 2 & ns & 2 & 1 & - & 0 & 1 & 2 & ns \\
\hline Crenosoma vulpis & 1 & 0 & ns & 1 & 0 & - & 0 & 1 & 0 & ns \\
\hline \multicolumn{11}{|l|}{ Intestinal parasites } \\
\hline Toxocara canis & 36 & 54 & ns & 80 & 10 & 0.0019 & 13 & 53 & 24 & ns \\
\hline Trichuris vulpis & 32 & 48 & ns & 51 & 29 & 0.0032 & 13 & 53 & 14 & ns \\
\hline Ancylostomatidae & 26 & 28 & ns & 51 & 3 & 0.0009 & 12 & 31 & 11 & ns \\
\hline Coccidia & 4 & 8 & ns & 9 & 3 & ns & 3 & 6 & 3 & ns \\
\hline Toxascaris leonina & 3 & 5 & ns & 8 & 0 & ns & 4 & 4 & 0 & 0.009 \\
\hline Aonchotheca putorii & 4 & 4 & ns & 8 & 0 & ns & 0 & 5 & 3 & ns \\
\hline Hymenolepis diminuta & 4 & 1 & - & 3 & 2 & - & 1 & 1 & 3 & - \\
\hline Dipylidium caninum & 1 & 0 & - & 1 & 0 & - & 0 & 1 & 0 & - \\
\hline Physaloptera spp. & 0 & 1 & - & 1 & 0 & - & 0 & 1 & 0 & - \\
\hline
\end{tabular}

cadiorespiratory and intestinal species. Prevalences found by flotation examination are summarized in Table 1. The most frequent intestinal parasites were Toxocara canis $(20.0 \%)$, Trichuris vulpis (17.8\%), Ancylostomatidae (12\%), Coccidia (2.7\%), Aonchotheca putorii (1.8\%) and Toxascaris leonina (1.8\%). The cardio-respiratory species found were Eucoleus aerophilus (9.6\%), Eucoleus boehmi (1.6\%), Angiostrongylus vasorum (0.7\%) and Crenosoma vulpis $(0.2 \%)$. Larvae of the two last species were detected in the same dogs also using Baermann's technique. No Taenidae eggs were found.

Table 2 reports the results of the statistical comparison of parasitic frequencies among gender, lifestyle and age groups. As for gender, a significant statistical difference was found for $E$. aerophilus ( $P$ value $=0.0263$ ), where female dogs were more frequently infected $(13.2 \%)$ than males $(6.9 \%)$. As for lifestyle, significant differences were found for some parasitic species. Hunting dogs were more frequently infected than non hunting dogs in the case of E. aerophilus (the frequencies were $12.5 \%$ and $0 \%$ respectively), T. canis (hunting $23.3 \%$, non hunting $9.4 \%$ ) and Ancylostomatidae (hunting $14.8 \%$, non hunting $2.8 \%$ ), while the opposite was true for E. boehmi (hunting $0.6 \%$ and non hunting $4.7 \%$ ) and for T. vulpis (hunting $14.8 \%$ and non hunting $27.4 \%$ ). Concerning age classes, young dogs $(21.1 \%)$ were more frequently infected than middle age $(8.6 \%)$ or old dogs $(6.5 \%)$ in the case of $E$. aerophilus. The same was true for $T$. leonina (young dogs $7.0 \%$, middle age dogs $1.5 \%$ and old dogs $0 \%$ ). These last differences were likely due to the sample.
A total of 116 dogs were parasitized by a single species: of these, 12 dogs harboured $E$. aerophilus and two E. boehmi, while the remaining 102 dogs were infected by a single intestinal parasite species, the most frequent being $T$. canis (41 dogs) and T. vulpis (37 dogs).

Multiple infections were observed in 81 dogs (18.0\%). One dog presented six different parasite species (E. aerophilus, $A$. vasorum, $C$. vulpis, T. canis, Coccidia and D. caninum) and another dog presented five different species (E. aerophilus, T. canis, T. vulpis, Ancylostomatidae and $T$. leonina). Five dogs presented 4 species of parasites, one cardiorespiratory and three intestinal parasites. Five dogs were infected by 3 species, one cardiorespiratory and two intestinal and 13 were infected by 3 species of intestinal parasites. The infections with 2 species were as follows: 24 infections by one cardiorespiratory and one intestinal parasites, one infection by two cardiorespiratory parasites ( $E$. aerophilus and $A$. vasorum), and 31 infections by two intestinal parasites.

\section{Discussion}

The interest in intestinal helminths of domestic dogs and cats has somewhat declined over the few last years in the developed world, because the routine use of certain anthelmintics, especially in puppies, is believed to have reduced their diffusion and impact on animal health and welfare (Robertson et al., 2000; Traversa et al., 2012). Conversely, more attention has been given to extraintestinal parasites, due to the increased number of cases, mainly of 
cardiorespiratory nematodes, described over the last decade (e.g. Caro-Vadillo et al., 2005; Staebler et al., 2005; Callegari et al., 2010; Di Cesare et al., 2011). In fact, many epidemiological surveys and reports have shown that these parasites are more common than previously thought, suggesting the potential underestimation of extraintestinal species, or, in some cases, the expansion of their geographical range (Conboy, 2009; Genchi et al., 2011). While their underestimation could be due to the lack of appropriate diagnostic techniques (Conboy, 2009), the expansion of their geographical range can be explained by the increased mobility of pets and the possible interaction among dogs and wild canids, which are the reservoir of such parasites (Genchi et al., 2011; Otranto et al., 2015). In the present study, $43.8 \%$ of dogs were found to be parasitized. A considerable number of dogs presented a mixed infection (8.0\%), $3.3 \%$ were infected only by cardiorespiratory species and $32.4 \%$ only by intestinal species.

Among cardiorespiratory parasites, of particular interest is $A$. vasorum, which is a metastrongyloid nematode that lives on the right side of the heart and pulmonary arteries of dogs, foxes and other wild carnivores and may be responsible for severe clinical symptoms. Following the first description in southern France in a dog (Serres, 1854), this species has frequently been found in foxes and more rarely in dogs (Koch \& Willesen, 2009). In the last decade, the number of reports in dogs has risen, showing that the parasite is widely distributed throughout Europe with prevalences varying from 0.3 to 2.2 (Papazahariadou et al., 2007, Greece; Taubert et al., 2009, Germany; Al-Sabi et al., 2013, Denmark; Shukullari et al., 2015, Albania).

Several reports have also been made in Italy. Clinical cases have been described in Tuscany (Della Santa et al., 2002), Abruzzo (Traversa et al., 2008), Apulia (Sasanelli et al., 2008) and Campania (Rinaldi et al., 2010). Epidemiological surveys have also been conducted in central Italy, where $0.4 \%$ of 239 client-owned dogs examined were found to be positive (Riggio et al., 2013) and in central and southern Italy, where $0.96 \%$ of 534 individual dogs and $2.48 \%$ of 471 kennel dogs were positive (Di Cesare et al., 2011).

In the study area investigated in the present survey, the prevalence at necropsy of $A$. vasorum in 165 foxes was very high (78.2 \%)(Magi et al., 2015). Conversely, among the 450 examined dogs, only three were found positive for the larvae of this parasite by faecal examinations $(0.7 \%)$. Although the prevalence values are not directly comparable since different diagnostic techniques were used in dogs and foxes, it is known that dogs appear to be far less frequently infected by this parasite than wild canids (Koch \& Willesen, 2009), as observed in the study area. In fact, some authors consider canine angiostrongylosis as an epiphenomenon of the cycle "gasteropoda-fox" (Bolt et al., 1994). This is likely due to the low palatability for dogs of the intermediate hosts of $A$. vasorum (mainly slugs and snails), and only partially to limitations concerning the coprological diagnosis. The Baermann technique for the detection of larvae L1 in faeces is currently the elective diagnostic method. However, it has a low sensitivity in terms of in- termittent larval excretion, and a low parasite burden or prepatent period (Oliveira-Junior et al., 2006; Taubert et al., 2009). Serological methods have thus been developed. Testing a subset of dog serum samples $(n=347)$ belonging to this study with an ELISA test for $A$. vasorum antigens and antibodies, a higher prevalence was found in the area $(0.3 \%$ with Baermann method, $0.6 \%$ with the ELISA tests) (Guardone et al., 2013).

C. vulpis was found only in one dog $(0.2 \%)$. This species is endemic in the red fox in Europe and North America and was found with a prevalence of $15.8 \%$ in foxes in the study area (Magi et al. 2015). It appears to be rarer in dogs. The first report in a domestic dog occurred in Great Britain (Cobb \& Fisher, 1992), followed by a few cases in Ireland (Reilly et al., 2000), Switzerland (Unterer et al., 2002) and Germany (Barutzki \& Schaper, 2003). The prevalence in dogs found in this study is slightly lower than the values found in Germany ( $0.9 \%$ of 8438 dogs examined, Barutzki \& Schaper, 2003; $2.4 \%$ of 958 dogs Taubert et al., 2009) and in Denmark (1.4\% of 4151 dogs Taubert et al., 2009 ). In Italy C. vulpis was reported for the first time in a dog in Campania by Rinaldi et al., (2007), and was recently found in kennels (18.4\% of the examined kennels) in the same region (Rinaldi et al., 2012). Respiratory capillariosis by E. aerophilus and E. boehmi are considered to be sporadic in pets, although the results of many studies in Italy and in other countries suggest that the presence of these two nematodes in domestic animals is most likely an underestimation (Burgess et al., 2008; Madeira de Carvalho et al., 2009; Di Cesare et al., 2011; Clark et al., 2013; Riggio et al., 2013; Veronesi et al., 2013). This could be due to various difficulties in coprological diagnosis, since, without a careful morphometrical and morphological analysis, eggs of $E$. aerophilus and of $E$. boehmi can be confused with those of the better known intestinal parasite, Trichuris vulpis (Magi et al., 2012; Macchioni et al., 2013). One of the most reliable distinctive characteristics is the external structure of the shell (Zarnowsky \& Patyk 1960), which can be clearly visualized using SEM (Traversa et al., 2011; Magi et al., 2012).

In this study $E$. aerophilus was found with a prevalence of $9.6 \%$, which is slightly higher than the values reported in the south of Italy by Traversa et al., 2009 (2.8\% of 569 dogs examined) and lower than those reported by Di Cesare et al., in 2011 (20.22\% of 534 dogs examined). This parasite, like the preceding ones, is generally found more frequently in foxes. In Liguria its prevalence in foxes was $41.8 \%$ at necropsy, and $25.5 \%$. at copromicroscopy (Magi et al., 2015).

The finding of $E$. boehmi in dogs in the study area represents one of the first reports of this parasite in Italy (De Liberato et al., 2009; Veronesi et al., 2013). The prevalence (5.3\%) was similar to the value found by De Liberato et al., 2009 (6.8\% out of 619 dogs examined). To the best of the authors' knowledge, reports of nasal capillariasis in European dogs have only been found in Poland (Gajewska et al., 2004) and in Italy (De Liberato et al., 2009; Veronesi et al., 2013). Three adult worms of $E$. boehmi were collected from the nasal cavities of a fox examined in the study area (Magi et al., 2015). 
Among intestinal parasites, T. canis (prevalence $20 \%$ ), T. vulpis $(17.8 \%)$ and Ancylostomatidae (12\%) were the most prevalent species in dogs in this survey. Their presence in the study area is not surprising, since these intestinal nematodes are frequently found in dogs in Europe (see Claerebout et al., 2009 and references therein).

In analogous recent studies: in northern Italy T. canis, Ancylostomatidae and T. vulpis were found with prevalences of $9.7 \%$, $8.2 \%$ and $29.2 \%$ respectively among 318 kennel dogs (Simonato et al., 2015). A study of 592 dogs found Toxocara spp. in $1.35 \%$ of the environmental samples, in $5.64 \%$ of the farm dogs and in $2.97 \%$ of the hunting dogs; Ancylostomatidae in $19.59 \%$ of the environmental samples, in $14.87 \%$ of the farm dogs and $20.79 \%$ of the hunting dogs, and T. vulpis in $11.49 \%$ of the environmental samples, in $16.41 \%$ of the farm dogs, and in $5.94 \%$ of the hunting dogs (Mateus et al., 2014).

In the same study area of the present survey, the prevalence of $T$. canis in foxes was $26.7 \%$ at necropsy and $18.3 \%$ at coproscopy (Magi et al., 2015), similar to the prevalence found in dogs. Also T. vulpis, with a prevalence of $21.1 \%$ at necropsy and $18.3 \%$ at coproscopy in foxes, showed similar values to the prevalence in dogs. Conversely, Ancylostomatidae appeared to be more frequent in foxes, with $70 \%$ by necropsy and $47.2 \%$ by coproscopy (Magi et al., 2015).

Toxascaris leonina was rarer in dogs than the above-mentioned intestinal parasites, most likely because the transmission occurs mainly with the ingestion of third stage larvae (L3) in infected paratenic hosts. In fact, the positive cases in this study were found only in hunting dogs, which are more likely to ingest paratenic hosts (however the difference was not statistically significant). The prevalence of these nematodes in Liguria adds to the data reported by other authors in other Italian regions such as in central Italy (1.7\% of 239 client-owned dogs examined, Riggio et al., 2013) and in northern Italy (10.02\% of 253 client-owned dogs, Zanzani et al., 2010).

In eight hunting dogs, capillarid eggs of $A$. putorii were identified by accurate morphological analysis according to the description given in Campbell et al. (1991). The presence of this parasite in dogs has not been reported before in Italy, however its presence in foxes in the same area (Magi et al., 2015) and the broad host range of the parasite suggests that it could also be present in dogs. SEM and biomolecular analysis are still ongoing for this trichuroid.

Physaloptera spp. was found in the faecal examination of one hunting dog. Physaloptera spp. have rarely been reported in domestic canids as being responsible for gastric disease (Burrows, 1983). Reports concern mainly the Middle East and South America (Clark, 1990; Theisen et al., 1998). However, the presence of the parasite in foxes in the same area (8.9\% at necropsy, Magi et al., 2015) may be the source of infection in the hunting dog.

As widely recognized, coprological flotation only has low sensitivity for the diagnosis of cestodes. The only cestodes found in dogs in this survey were Hymenolepis diminuta in five dogs $(1.12 \%)$ and
Dipylidium caninum in one dog $(0.22 \%)$. D. caninum is frequently found in domestic carnivores, while the presence of $H$. diminuta is rare (Guardone et al., 2010).

In fact, $H$. diminuta is a common parasite of rodents, which can sometimes infect humans, monkeys and dogs (Neveu-Lemaire, 1936). There are very few data in the literature on the presence of $H$. diminuta in dogs. The only confirmed case of intestinal infection was found at necropsy in a dog in Africa (Gomes et al., 2000). While in many cases $H$. diminuta eggs have been attributed to spurious infections (Miterpakova et al., 2009), in the present study the positivity of one kennel dog was confirmed in different faecal samples over a 3-week period, suggesting true infection, at least in this case, and not the ingestion of an infected rodent (Guardone et al., 2010). The main intermediate hosts of $H$. diminuta are grain beetles, flour beetles and fleas while the definitive hosts are dogs, cats and wild carnivores. Humans acquire the parasite in case of accidental ingestion of intermediate hosts, possibly with contaminated flour, cereal products, or dried fruits. Human infections are sporadic but occur worldwide and mainly occur in children (Hamrick et al., 1990). In Italy it was recently diagnosed in a child from Sicily (Patamia et al., 2010) and previously in Rome (Marangi et al., 2003) and Alessandria (Scaglione et al., 1990).

\section{Conclusions}

This study revealed a significant presence of parasites of zoonotic importance in dogs living in rural and semirural environments in an area of Liguria. The sample population was chosen in order to examine dogs with potential close contact with foxes, considering that close contact between humans, domestic and wild canids may have significant public health implications.

Understanding and studying the epidemiology of zoonotic parasitic infections is important in order to minimize the risks to humans (Mateus et al., 2014). Health education should therefore be developed in order to defend the population against the risks resulting from infections especially in children. In rural areas, farmers and hunters should be addressed in particular. Of particular interest is the detection of cardio respiratory parasites in an area that has never previously been investigated. The extension of the sampling area, on a provincial basis, is needed in order to build a more detailed map of prevalences for different species of dog parasites throughout Liguria.

\section{References}

Aftandelians, R., Raafat, F., Taffazoli, M., Beaver, P.C. (1977): Pulmonary capillariasis in a child in Iran. Am. J. Trop. Med. Hyg., 26(1): $64-71$

Al-Sabi, M.N., Kapel, C.M., Johansson, A., Espersen, M.C., Koch, J., WILLESEN, J.L. (2013): A coprological investigation of gastrointestinal and cardiopulmonary parasites in hunting dogs in Denmark. Vet. Parasitol., 196(3): 366 - 372. DOI: 10.1016/j.vetpar.2013.03.027 
BARUTZKI, D., Schaper, R. (2003) Endoparasites of dogs and cats in Germany (1999 - 2002). Parasitol. Res., 90: 148 - 150. DOI: 10.1007/s00436-003-0922-6

Bolt, G., Monrad, J., Koch, J., Jensen, A.L. (1994): Canine angiostrongylosis: a review. Vet. Rec., 135: 447 - 452. DOI: 10.1136/ vr.135.19.447

BowmAn, D.D. (1987): Diagnostic morphology of four larval ascaridoid nematodes that may cause visceral larva migrans: Toaxascaris leonina, Baylisascaris procyonis, Lagochilascaris sprenti, and Hezametra leidyi. J. Parasitol., 73(6): 1198 - 1215. DOI: 10.2307/3282306

Bowman, D.D., Montgomery, S.P., Zajac, A.M., Eberhard, M.L., KAZACOS, K.R. (2010): Hookworms of dogs and cats as agents of cutaneous larva migrans. Trends Parasitol., 26: 162 - 167. DOI: 10.1016/j.pt.2010.01.005

Burgess, H., Ruotsalo, K., Peregrine, A.S., Hanselman, AbramsOGG, A. (2008): Eucoleus aerophilus respiratory infection in a dog with Addison's disease. Can. Vet. J., 49: 389 - 392

Burrows, C.F. (1983): Infection with the stomach worm Physaloptera as a cause of chronic vomiting in the dog. J. Am. Anim. Hosp. Assoc., 19: 947 - 950

Callegari, D., Kramer, L., Cantoni, A.M., Di Lecce, R., Dodi, P.L., GRANDI, G. (2010): Canine bladderworm (Capillaria plica) infection associated with glomerular amyloidosis. Vet. Parasitol., 168: 338 341. DOI: 10.1016/j.vetpar.2009.11.008

CAmpbelL, B.G. (1991): Trichuris and other Trichinelloid nematodes of dogs and cats in the United States. Comp. Cont. Educ. Pract., 13: $769-778$

Caro-Vadillo, A., Martínez-Merlo, E., García-Real, I., Fermín-Rodríguez, M.L., Mateo, P. (2005): Verminous pneumonia due to Filaroides hirthi in a Scottish terrier in Spain. Vet. Rec., 157: $586-589$

Claerebout, E., Casaert, S., Dalemans, C., De Wilde, N., Levecke, B., Vercruysse, J. Geurden, T. (2009): Giardia and other intestinal parasites in different dog populations in Northern Belgium. Vet. Parasitol., 161: 41 - 46. DOI:10.1016/j.vetpar.2008.11.024

CLARK, J.A. (1990): Physaloptera stomach worms associated with chronic vomition in a dog in Western Canada. Can. Vet. J., 31(12): 840

Clark, A.C., López, F.R., Levine, J.M., Cooper, J.J., Craig, T.M., Voges, A.K., Johnson, M.C., Porter, B.F. (2013): Intracranial migration of Eucoleus (Capillaria) boehmi in a dog. J. Small Anim. Pract., 54: 99 - 103. DOI: 10.1111/j.1748-5827.2012.01303.x

CobB, M.A., FISHeR, M.A. (1992): Crenosoma vulpis infection in a dog. Vet. Rec., 130: 452. DOI: 10.1136/Vr.130.20.452

ConBoy, G. (2009) Helminth parasites of the canine and feline respiratory tract. Vet. Clin. N. Am-Small., 39: 1109 - 1126. DOI: 10.1016/j.cvsm.2009.06.006

Della Santa, D., Citi, S., Marchetti, V., Nardoni, S. (2002): Infection by Angiostrongylus vasorum in dogs: literature review and presentation of a clinical case. Veterinaria, 16: 9 - 14 (In Italian) Deplazes, P., Hegglin, D., Gloor, S., Romig, T. (2004): Wilderness in the city: the urbanization of Echinococcus multilocularis. Trends Parasitol., 20: 77 - 84. DOI: 10.1016/j.pt.2003.11.011

Deplazes, P., Van Knapen, F., Schweiger, A., Overgaauw, P.A. (2011): Role of pet dogs and cats in the transmission of helminthic zoonoses in Europe, with a focus on echinococcosis and toxocarosis. Vet. Parasitol., 182: 41 - 53. DOI: 10.1016/j.vetpar.2011.07.014

De Liberato, C., Mazzanti, S., Scaramozzino, P. (2009): First report of Eucoleus bohmi (Nematoda Trichuridea) from Italy: parasitological findings and veterinary implications. Parassitologia, 51: $43-45$ Di Cesare, A., Castagna, G., Meloni, S., Milillo, P., Latrofa, S., Otranto, D.,Traversa, D. (2011): Canine and feline infections by cardiopulmonary nematodes in central and southern Italy. Parasitol. Res., 109(1): 87 - 96

Dryden, M.W., Payne, P.A.,Ridley, R., Smith, V. (2005): Comparison of common fecal flotation techniques for the recovery of parasite eggs and oocysts. Vet. Ther., 6: $15-28$

Eckert, J., Deplazes, P. (2004): Biological, epidemiological, and clinical aspects of echinococcosis, a zoonosis of increasing concern. Clin. Microbiol. Rev., 17(1): 107 - 135. DOI: 10.1128/ CMR.17.1.107-135.2004

Gajewska, A., Gorski, P., Kotomski, G., Bogdanowicz, M., KlockieWICZ, M., KazIMIERCZAK, K. (2004): Changes in parasites of dogs and cats from Warsaw and suburbs during the period of $1974-2002$. Part III. Roundworms. Zycie Wet., 79: 208 - 212 (In Polish)

Genchi C., Kramer L.H., Rivasi, F. (2011): Dirofilarial infections in Europe. Vector Borne Zoonotic Dis., 10: 1307 - 1317. DOI: 10.1089/vbz.2010.0247

Gomes, A.F. (2000): Intestinal parasitic infections of stray dogs from Huambo, Angola. Rev. Port. Cienc. Vet.. Revista., 535: 129 - 133 Guardone, L., Macchioni, F., Torracca, B., Gabrielli, S., Magi, M. (2010): Hymenolepis diminuta (rat tapeworm) infection in a dog in Liguria, North-western Italy. In Proceedings of the $26^{\text {th }}$ Conference of the Italian Society of Parasitology (SoIPA.), $22^{\text {nd }}-25^{\text {th }}$,June 2010. Perugia, Italy

Guardone, L., Schnyder, M., Macchioni, F., Deplazes, P., Magi, M. (2013): Serological detection of circulating Angiostrongylus vasorum antigen and specific antibodies in dogs from central and Northern Italy. Vet. Parasitol., 192(1 - 3): 192 - 198. DOI: 10.1016/j.vetpar.2012.10.016

Hamrick, H.J., BowdRe, J.H., ChURCH, S.M. (1990): Rat tapeworm (Hymenolepis diminuta) infection in a child. Pediatr. Infect. Dis. J., 9(3): $216-219$

KoCH, J., WILlesen, J.L. (2009): Canine pulmonary angiostrongylosis: An update. Vet. J., 179: 348 - 359. DOI: 10.1016/j. tvjl.2007.11.014

JeNKINS, E.J., Schurer, J.M., Gesy, K.M. (2011): Old problems on a new playing field: Helminth zoonoses transmitted among dogs, wildlife, and people in a changing northern climate. Vet. Parasitol.,182(1): 54 - 69. DOI: 10.1016/j.vetpar.2011.07.015

Lalošević, D., Lalošević, V., Klem, I., Stanojev-Jovanović, D., Pozıo, E. (2008): Pulmonary capillariasis miming bronchial carcinoma. Am. J Trop. Med. Hyg., 78: $14-16$ 
Lee, A.C., Schantz, P.M., Kazacos, K.R., Montgomery, S.P., BowMAN, D.D. (2010): Epidemiologic and zoonotic aspects of ascarid infections in dogs and cats. Trends Parasitol., 26(4): 155 - 161. DOI: 10.1016/j.pt.2010.01.002

Macchioni, F., Guardone, L., Prati, M.C., Magi, M. (2013): Eucoleus aerophilus (syn. Capillaria aerophila) and other trichinelloid nematodes in dogs from Liguria (northwest Italy). In: Trends in Veterinary Sciences. Springer Berlin Heidelberg, pp. 85 - 89

Madeira, De Carvalho, L.M., Pereira, Da Fonseca, L.M., Gomes, L., MeIRELES, J.M. (2009): Lungworms in domestic and wild carnivores in Portugal: rare parasites or rarely diagnosed? In Proceedings of the Bayer Angiostrongylosis Forum, 19 $9^{\text {th }}$ Annual Congress of the European College of Veterinary Internal Medicine - Companion Animals, 9 September 2009. Porto, Portugal

Magi, M., Guardone, L., Prati, M.C., Torracca, B., Macchioni, F. (2012): First report of Eucoleus boehmi (syn. Capillaria boehmi) in dogs in north-western Italy, with scanning electron microscopy of the eggs. Parasite, 19(4): 433 - 435. DOI: 10.1051/parasite/2012194433

Magi, M., Guardone, L., Prati, M.C., Mignone, W., Macchioni, F. (2015): Extraintestinal nematodes of the red fox Vulpes vulpes in north-west Italy. J. Helminthol., 89(4): 506 - 511. DOI: 10.1017/ S0022149X1400025X

Magi, M., Guardone, L., Mignone, W., Monni, G., Tozzinı, G., PraTI, M. C., MACCHIONI, F. (2016): Canine filarial infections in Liguria, north-west Italy. J. Helminthol., 90(1): 121 - 124. DOI: 10.1017/ S0022149X15000012

Marangl, M., Zechini, B., Fileti, A., Quaranta, G., Acetı, A. (2003): Hymenolepis diminuta infection in a child living in the urban area of Rome, Italy. J. Clin Microbiol., 41(8): 3994 - 3995. DOI: 10.1128/ JCM.41.8.3994-3995.2003

Martínez-Moreno, F.J., Hernández, S., López-Cobos, E., Becerra, C., Acosta, I., Martínez-Moreno, A. (2007): Estimation of canine intestinal parasites in Córdoba (Spain) and their risk to public health. Vet. Parasitol., 143: 7 - 13. DOI: 10.1016/j.vetpar.2006.08.004

Mateus, T.L., Castro, A., Ribeiro, J.N., Vieira-Pinto, M. (2014): Multiple zoonotic parasites identified in dog feces collected in Ponte de Lima, Portugal - a potential threat to human health. Int. J. Environ. Res. Publ. Health., 11(9): 9050 - 9067. DOI: 10.3390/ ijerph110909050

Miterpáková, M., Hurníková, Z., Antolová, D., Dubinský, P. (2009): Endoparasites of red fox (Vulpes vulpes) in the Slovak Republic with the emphasis on zoonotic species Echinococcus multilocularis and Trichinella spp. Helminthologia, 46(2): 73 - 79. DOI: 10.2478/ s11687-009-0015-X

NeVEu-Lemaire, M. (1936): Medical and veterinary treatise of helminthology. Paris, Vigot Frères Editeures. 1514 pp. (In French) Oliveira-Junior, S.D., Barçante, J.M.P., Barcante, T.A., Dias, S.R.C., LIMA, W.S. (2006): Larval output of infected and re-infected dogs with Angiostrongylus vasorum (Baillet, 1866) Kamensky, 1905. Vet. Parasitol., 141(1):101 - 106. DOI: 10.1016/j.vetpar.2006.05.003
Otranto, D., Cantacessi C., Dantas-Torres, F., Brianti, E., Pfeffer, M., Genchi, C., Guberti, V., Capelli, G., Deplazes, P. (2015): The role of wild canids and felids in spreading parasites to dogs and cats in Europe. Part II: Helminths and arthropods. Vet. Parasitol., 213(1 - 2): 24 - 37. DOI: 10.1016/j.vetpar.2015.04.020

Papazahariadou, M., Founta, A., Papadopoulos, E., Chliounakis, S., Antoniadou-Sotiriadou, K., TheOdorides, Y. (2007): Gastrointestinal parasites of shepherd and hunting dogs in the Serres Prefecture, Northern Greece. Vet. Parasitol., 148: 170 - 173. DOI: 10.1016/j. vetpar.2007.05.013

Patamia, I., Cappello, E., Castellano-Chiodo, D., Greco, F., Nigro, L., Cacopardo, B. (2010): A human case of Hymenolepis diminuta in a child from eastern Sicily. Korean J. Parasitol., 48(2): 167 169

Reilly, G.A., Mcgarry, J.W., Martin, M., Belford, C. (2000): Crenosoma vulpis, the fox lungworm, in a dog in Ireland. Vet. Rec., 146: $764-765$

Riggio, F., Mannella, R., Ariti, G., Perrucci, S. (2013): Intestinal and lung parasites in owned dogs and cats from central Italy. Vet. Parasitol., 193(1): 78 - 84. DOI: 10.1016/j.vetpar.2012.11.026

Rinaldi, L., Calabria, G., Carbone, S., Carrella, A., Cringoli, G. (2007): Crenosoma vulpis in dog: first case report in Italy and use of the FLOTAC technique for copromicroscopic diagnosis. Parasitol. Res., 101: 1681 - 1684. DOl:10.1007/s00436-007-0713-6

Rinaldi, L., Cortese, L., Pennacchio, S., Santaniello, A., Carbone, S., Maiolino, P., Ciaramella, P., Cringoli, G. (2010): Fatal case of angiostrongylosis in a dog and use of FLOTAC for diagnosis. Parassitologia, 52: 253

Rinaldi, L., Pennacchio, S., Musella, V., Maurelli, M.P., Guariglia, I., Capelli, G., Cringoli, G. (2012): Kennel dogs and helminth infections in the Campania region. In Proceedings of the 27th Conference of the Italian Society of Parasitology (SO.I.PA.), $26^{\text {th }}-29^{\text {th }}$ June 2012. Alghero, Italy

Robertson, I.D., IRWIN, P.J., Lymbery. A.J.,Thompson, R.C.A. (2000): The role of companion animals in the emergence of parasitic zoonoses. Int. J. Parasitol. Res., 30: 1369 - 1377 DOI: 10.1016/ S0020-7519(00)00134-X

Sasanelli, M., Paradies, P., Otranto, D., Lia, R.P., De Caprarils, D. (2008): Haemothorax associated with Angiostrongylus vasorum infection in a dog. J. Small Anim. Prac., 49: 417 - 419 DOI: 10.1111/j.1748-5827.2008.00551.x

Scaglione, L., Troielli, F., Ansaldi, E., Orsi, P.G., Garavelli, P.L. (1989): Hymenolepis diminuta: a rare helminthiasis in humans. Description of a clinical case. Minerva Med., 81: 65 - 67 (In Italian) SERRES, E. (1854): Entozoa found in the right atrium, the corresponding ventricle and the pulmonary artery of a dog. J. Vét. du Midi, 7: 70 (In French)

Shukullari, E., Hamel, D., Rapti, D., Pfister, K., Visser, M., Winter, R., ReHBEIN, S. (2015): Parasites and vector-borne diseases in client-owned dogs in Albania. Intestinal and pulmonary endoparasite infections. Parasitol. Res., 114(12): 4579 - 4590. DOI: 10.1007/ s00436-015-4704-8 
Simonato, G., Di Regalbono, A.F., Cassini, R., Traversa, D., Beraldo, P., Tessarin, C., Pietrobelli, M. (2015): Copromicroscopic and molecular investigations on intestinal parasites in kenneled dogs. Parasitol Res., 114(5): 1963 - 1970. DOI: 10.1007/s00436-015-4385-3 Soriano, S.V., Pierangeli, N.B., Roccia, I., Bergagna, H.F., Lazzarini, L.E., Celescinco, A., Saiz, M.S., Kossman, A., Contreras, P.A., ARIAS, C., BASUALDO, J.A. (2010): A wide diversity of zoonotic intestinal parasites infects urban and rural dogs in Neuquén, $\mathrm{Pa}$ tagonia, Argentina. Vet. Parasitol., 167: 81 - 85. DOI: 10.1016/j. vetpar.2009.09.048

Staebler S., Ochs H., Steffen F., Naegeli F., Borel N., Sieber-RuckStuhl N., Deplazes P. (2005): Autochthonous infections with Angiostrongylus vasorumin dogs in Switzerland and Germany. Schweiz. Arch. Tierheilkd., 147: 121 - 127

Taubert, A., Pantchev, N., Vrhovec, M.G., Bauer, C., Hermosilla, C. (2009): Lungworm infections (Angiostrongylus vasorum, Crenosoma vulpis, Aelurostrongylus abstrusus) in dogs and cats in Germany and Denmark in 2003 - 2007. Vet. Parasitol., 159: 175 - 180. DOI: 10.1016/j.vetpar.2008.10.005

TAYLOR, M.A., COOP, R.L., WALL, R.L. (2007): Veterinary Parasitology. Third Edition Blackwell Publishing, Oxford, UK

Theisen, S.K., Le Grange, S.N., Johnson, S.E., Sherding, R.G., Willard, M.D. (1998): Physaloptera infection in 18 dogs with intermittent vomiting. J. Am. Anim. Hosp. Assoc., 34: 74 - 78. DOI: 10.5326/15473317-34-1-74

Traversa, D., Torbidone, A., Malatesta, D., Guglielmini, C. (2008): Occurrence of fatal canine Angiostrongylus vasorum infection in Italy. Vet. Parasitol., 152: 162 - 166 DOI: 10.1016/j.vetpar.2007.12.009

Traversa, D., Di Cesare, A.D., Milillo, P., lorio, R., Otranto, D. (2009): Infection by Eucoleus aerophilus in dogs and cats: is another extra-intestinal parasitic nematode of pets emerging in Italy?
Res. Vet. Sci., 87(2): 270 - 272 DOI: 10.1016/j.rvsc.2009.02.006 TraversA, D. (2011): Are we paying too much attention to cardio-pulmonary nematodes and neglecting old-fashioned worms like Trichuris vulpis. Parasite. Vector., 4: 32

TRAVERSA, D. (2012): Pet roundworms and hookworms: a continuing need for global worming. Parasite. Vector., 5(1): 91 - 110

Unterer, S., Deplazes, P., Arnold, P. Flückiger, M., Reusch, C.E., Glaus, T.M. (2002): Spontaneous Crenosoma vulpis infection in 10 dogs: laboratory, radiographic and endoscopic findings. Schweiz. Arch. Tierheilkd., 144: 174 - 179. DOI: 10.1024/00367281.144.4.174

Xhaxhiu, D., Kusi, I., Rapti, D., Kondi, E., Postoli, R., Rinaldi, L., Dimitrova, Z.M., Visser, M., Knaus, M., Rehbein, S. (2011): Principal intestinal parasites of dogs in Tirana, Albania. Parasitol. Res., 108: 341 - 353. DOI: 10.1007/s00436-010-2067-8

Veronesi, F., Lepri, E., Morganti, G., Di Palma, S., Mechelli, L., Moretti, A., Traversa D. (2013): Nasal eucoleosis in a symptomatic dog from Italy. Vet. Parasitol.,195(1): 187 - 191. DOI: 10.1016/j. vetpar.2013.01.022

Vervaeke, M., Dorny, P., De Bruyn, L., Vercammen, F., Jordaens, K., Van Den Berge, K., Verhagen, R. (2005): A survey on intestinal helminths of the red foxes (Vulpes vulpes) in Northern Belgium. Acta Parasitol., 50(3): 221 - 227

Yamaguti, S. (1959): Systema Helmintum. New York, Intersciences Publisher inc. $1261 \mathrm{pp}$.

Zanzani, S., Bonassi, L., Maffi, S., Mandredi M.T. (2010): Prevalence of intestinal parasites in dogs and cats from two provinces of Lombardy region and perception of related risks by the pet owners. Parassitologia, 52(1 - 2): 341

ZARnOWSKY, E., PATYK, W. (1960): On the independence of the species Thominx böhmi (Supperer, 1953) and its occurrence. Acta Parasitol., 8: $205-213$ 